\title{
The role of organizational climate in socially embedding construction firms'sustainability goals
}

Article

Accepted Version

Phua, F. T. T. (2018) The role of organizational climate in socially embedding construction firms'sustainability goals. Construction Management and Economics, 36 (7). pp. 409421. ISSN 0144-6193 doi:

https://doi.org/10.1080/01446193.2018.1424348 Available at https://centaur.reading.ac.uk/74870/

It is advisable to refer to the publisher's version if you intend to cite from the work. See Guidance on citing.

To link to this article DOI: http://dx.doi.org/10.1080/01446193.2018.1424348

Publisher: Taylor \& Francis

All outputs in CentAUR are protected by Intellectual Property Rights law, including copyright law. Copyright and IPR is retained by the creators or other copyright holders. Terms and conditions for use of this material are defined in the End User Agreement.

www.reading.ac.uk/centaur 
Central Archive at the University of Reading

Reading's research outputs online 


\title{
The role of organizational climate in socially embedding construction firms' sustainability goals
}

\begin{abstract}
Despite the growing interest in sustainability research, little scholarly attention, both conceptual and empirical, has been given to assessing the individual-level behavioural issues that affect sustainability outcomes. Still less research is undertaken to examine the mechanisms by which construction firms enable their sustainability goals to be socially embedded within their organizations to shape the behaviour and attitudes of employees. In an attempt to fill this gap, this paper draws extensively from the literature on organizational climate perspective to explain how organizational-level characteristics and processes can result in a strong, conducive climate that fosters shared perceptions and guide behaviours that are fundamental to the attainment of sustainability goals in organizations. From the critical review of this literature, this paper offers three research propositions and avenues in which they could be tested. The paper concludes with a broadened discussion of the theoretical and practical implications this framework has on advancing the sustainability discourse within CM discipline beyond the current largely technical, policy and institutional foci.
\end{abstract}

Keywords: sustainability, organizational climate, culture, behaviour, shared perceptions, sensemaking 


\section{Introduction}

As the sustainability agenda gathers pace in recent years (e.g. Department of Business, Enterprise and Regulatory Reform 2008, Department for Business, Energy and Industrial Strategy, 2013), so does the amount of research aimed at exploring the factors that either promote or inhibit it at regional, national and even international levels (Department for Environment, Food \& Rural Affairs, 2010-2017; United Nations, 2015). In the construction management (CM) and building disciplines, the majority of this work is centred on the technical, economic and policy aspects (e.g. Bob and Hutchinson, 2000; Torriti, 2012; Nicol, 2011; Fawcett et al., 2012; Gluch et al., 2009; Lowe and Oreszczyn, 2008; van Bueren and de Jong, 2007; Lomas, 2009; Schweber et al., 2015). For instance, technical research following Hill and Bowen's (1997) proposal of setting 'over-arching, process-oriented principles, to be used as a checklist' (p.223) for sustainable construction is still commonly found (e.g. du Plessis, 2007; Huang and Hsu, 2011). Other studies focusing on the technical aspects of sustainability are those that look at, for example, the life cycle analysis of construction components (e.g. Bianchini and Hewage, 2012) or the assessment indicators of sustainability (e.g. Shen et al,. 2011). In conjunction with this line of research, there is also a growing recognition that sustainability research needs to take more seriously the impact of the underlying social and behavioural factors that contribute to the successes or failures of sustainability-related policies and technological uptake (Oreszczyn and Lowe, 2010; Berardi, 2013). This point is reinforced by du Plessis and Cole (2011) who commented that sustainable construction is largely driven by two main mechanisms: policy and regulatory instruments and, voluntary or regulated assessment and rating programmes. They called for a more holistic research approach that focuses on the social and behavioural aspects that address '...the very assumptions and values on which decisions are based in the design, construction and operation of the built environment...' (p.443). However, where researchers have focused specifically on the behavioural or social issues, they tend to emphasize 
mostly on the occupants and broader societal and cultural contexts (e.g. Li and Yao, 2012; Rijala et al. 2009; Bergman and Eyre, 2011; Summerfield et al. 2010).

Against this backdrop of existing research, there is a dearth of work on the role that firms play in advancing their sustainability goals ${ }^{1}$. In response to the many institutional, market and policy conditions (Teece et al 1997; Oliver, 1991), many firms find themselves at the intersection of adapting either their core business practices or diversifying into new, niche or mainstream markets in order to be more sustainably oriented. One practical example of how institutional pressures affect market demand and supply and hence, firms' business operations in the UK is BREEAM's (http://www.breeam.org/) guidelines for sustainable construction. Although essentially a voluntary scheme, firms, be they clients, developers, manufacturers or designers who are keen to promote their sustainability and environmental credentials do so by adhering to its various quality assurance certifications, and this in turn, influence to some extent their core business functions and processes (Schweber and Leiringer, 2012). As more firms in the construction supply chain adopt some form of sustainable construction practices the imperative for researchers and practitioners to understand how these firms configure and organize themselves in terms of their resources, capabilities etc. to achieve their organizational objectives become obvious. In 'mainstreaming sustainability', as Boyd and Schweber (2012) put it, many construction firms still find it a major challenge to integrate sustainability into their everyday business. This point has been reinforced by Mårtensson and Westerberg (2016) who argued that whilst many firms have adopted some form of programme to contribute to sustainable development, they tend to subscribe to a prosaic and 'weak' version of sustainability that neither challenges the concept of business as usual nor changes their unsustainable relationships with nature. They further added more often than not, environmental strategies are motivated by legislative or competitive considerations rather than forming part of

\footnotetext{
${ }^{1}$ This is taken to mean construction firms' strategic intent to advance the sustainability agenda which affects their core business operations and activities. In this paper, sustainability will be discussed and treated as an organizational-level outcome and it is therefore, distinct from sustainable methods of construction which is a) not the focused of this paper, and b) a project-level outcome.
} 
more fundamental values within the company (p.1). To this end, many studies have employed wellestablished theoretical frameworks such as the resource-based view (Barney, 1991), institutional processes (Oliver, 1991) and dynamic capabilities perspective (Teece et al., 1997) to identify and explain the variations in firm-level strategies and their outcomes with respect to sustainability development (e.g. Boyd and Schweber, 2012). This greatly improves and shapes more informed practice-oriented approaches to sustainability.

However, what is central but currently not well understood is the explanation of how construction firms have enabled their sustainability goals to become socially embedded within their organizations to shape behaviour and attitudes. This research inquiry is significant for two key reasons. First, at the industry level, if we accept that sustainability progress depends on placing greater attention to issues of organizational transformational change and operationalization, then in order to harness this potential, sustainable behaviour must become a source of competitive advantage (Scott and Rothman, 1994). This reinforces Schweber and Harty's (2010, p.671) view that if tools like BREEAM and other 'seemingly stable artefacts' are 'open to multiple interpretations by different users even in the same setting', then this would suggest the need to examine the drivers that are conducive for cultivating shared perceptions and behaviour across different stakeholders. This notion is further echoed by Fellows and Liu $(2012$, p.668) who suggested that 'the difficulties relating to communications and acceptance across boundaries of different communities of practice/knowledge must also address and overcome the self-interest orientation of those communities....That requires a gamut of changes - behaviour, climate and culture - requiring effort and reinforcement over the long term to be effective'.

Second, at the organizational level, research has found that the characteristics of an organization's internal work environments strongly shape employees' behaviours and attitudes (e.g. Schneider et al., 2002; Carr et al., 2003; Patterson et al., 2004). Therefore, it is imperative to investigate ways in which construction firms can elicit employee behaviours that are aligned with the firm's sustainability goals. This will consequently, promote core behaviours that are valued and 
rewarded in terms of achieving organizational sustainability goals. As Gladwin et al. (1995, p.899) aptly noted, 'the study of sustainability must shift from objective to subjective, from exterior nuts and bolts to interior hearts and minds'. Advancing knowledge from this 'interior', organizationallevel perspective is needed to further our understanding beyond the heavy focus currently placed on the technical, structural and policy aspects of sustainable research because fundamentally, human and social elements are just as important in bringing about sustainability outcomes.

This paper aims to address the existing research gap in sustainability research. It does so through the following research objectives. First, it discusses the development of organizational climate in mainstream management and organizational studies literature as a productive framework from which to study the relationships between climate-driven perceptions and organizational outcomes. Second, drawing from this extensive literature, it explains how a strong organizational climate generates employee behaviours that are valued and rewarded and how they accumulate to positively affect organizational effectiveness. Third, through presenting a critical review of this literature, the broader practical and theoretical implications of advancing a strong climate for sustainability for construction firms are discussed, followed by the inclusion of a conceptual framework and three research propositions to guide future research in this area.

\section{Defining organizational climate - what it is and what it is not}

A strong body of literature now exists to suggest that organizational climate has important implications for both individual work outcomes and organizational outcomes (see Kuenzi and Schminke (2009) and Schneider et al., (2013) for comprehensive review). Numerous studies over the years have demonstrated that as an empirically-verifiable entity, organizational climate acts as a source of influence for shaping individual attitudes and behaviours. More specifically, it has been recognised that the observable characteristics of an organization or work environment, such as the organizational structure, policies, procedures and practices have an impact on organizational groups and individuals (James and Jones, 1974; Joyce and Slocum, 1984; Schneider, 1990). Indeed, 
Schneider (1990) has written convincingly about the utility of organizational climate in explaining employee behaviour in organizational contexts. The extent to which organizational members have a shared and enduring perception of the important aspects of the work environment determines the strength of organizational climate. Perceptions of a strong climate reflect aspects that are psychologically meaningful to the individuals and these aspects tend to be both shared and resistant to change (Ashforth, 1985, p.837). While this conceptualization of organizational climate may appear to resemble the concept of organizational culture, in that both are concerned with the creation and influence of social contexts in organizations, they are two distinct constructs with differing epistemology, theoretical foundations and methodological assumptions.

In critically reviewing the literatures on the two constructs, Denison (1996), in one of the seminal discussion papers on the legitimacy of adopting a climate perspective, argued that although culture and climate are derived through interaction and socialization among group members, organizational culture is concerned with the historical evolution of social systems and the importance of understanding the underlying values and assumptions held by individuals, whereas the climate construct is not so much about the evolution but the impact that organizational systems have on organizational members. In short, the culture literature has sociological and anthropological roots while the climate literature stems from Lewinian field theory and psychology (Schneider, 1990). It also differs from organizational culture in that it emphasizes on observable aspects that are closer to the surface-level manifestations of organizational life. Denison (1996, p. 624) also usefully argued that the organizational climate literature fundamentally differs from the culture literature in that climate portrays organizational environment as rooted in an 'objective' set of organizational dimensions or salient organizational characteristics and the corresponding 'subjective' perceptions of individuals of those objective characteristics. Hence, organizational climate is regarded as relatively temporary and largely limited to those aspects of the social environment that are consciously perceived by organizational members. As a construct, it also 
implies that it is more malleable and can be subjected to direct control or manipulation by senior management within the organization.

Organizational culture, in contrast, refers to the deep structure of organizations which is underpinned by assumptions, values and beliefs. These assumptions and beliefs are often so deeply embedded that they are deemed to be unconscious, hidden and taken for granted and hence, culture is regarded to exist at a higher level of abstraction than climate (Schein, 2010). The dependence of organization members' subconsciously-derived cognition and action on the historical organizational system and the evolved organizational context gives culture greater stability and permanence, and hence less room for direct manipulation. Methodologically, the culture paradigm is traditionally researched using qualitative, inductive approaches that utilise an idiographic method relating to singular cases as is found in case studies. On the other hand, climate research is predominantly operationalized using quantitative, positivist methods that emphasize on nomothetic approaches that involve relatively large sample to provide a more comparative and generalizable outlook.

Although they are related but distinct constructs, over time the research boundary between organizational culture and organizational climate is blurred as culture researchers begin to apply the quantitative, comparative approaches associated with climate research (e.g. Hofstede, 1991, 2001; O’Reilly et al., 1991) while climate researchers have used an inductive, social constructionist framework to describe the evolution of organizational contexts (e.g. Ashforth, 1985). Despite the overlaps between these constructs, many researchers continue to argue for the need to identify and explain the intersecting relationship between organizational culture and climate (Moran and Volkwein, 1992). For the purpose of this paper, Schneider and Reichers's (1983) definition of organizational climate is used. It is defined as a set of shared perceptions regarding the policies, practices and procedures that an organization rewards, supports and expects. This conceptualisation distinguishes it from the more amorphous conceptualisation of culture because it focuses directly on the psychological processes by which shared perceptions are attended to rather than as in the case 
of culture studies, emphasizing on the manifestation of organizational phenomenon through artefacts and symbols to reveal the underlying shared beliefs and values. In other words, the extent to which organizational members agree in their perceptions of the policies, practices and procedures within a given organization context reflect the strength of the organizational climate. In this paper, the climate for sustainability will be discussed based on this conceptualisation so that it can be treated as a strategic function which firms deliberately want to bring about ${ }^{2}$, and also it enables researchers to operationalise it meaningfully.

\section{Organizational climate formation and development}

Evidence from a growing number of studies continues to demonstrate that a variety of different types of organizational climate that ranges from justice (e.g. Simons and Roberson, 2005), ethics (e.g. Martin and Cullen, 2006), safety (e.g. Neal and Griffin, 2006; Smith-Crowe et al., 2003) to service (e.g. de Jong et al., 2005) exert a strong influence on various organizational outcomes. For instance, it is found that a strong justice climate is related to stronger team performance and productivity; a strong ethical climate is related to stronger financial performance (through better governance structure); while a strong safety climate is reflected by reduced accident rates; and a strong service climate is related to improved sales performance. At the individual level, studies have also found links between strong climate and increased individual job satisfaction, organizational commitment and empowerment which renders it a reliable predictor of positive employee behaviour and attitudes (Kuenzi and Schminke, 2009). These studies and many others have looked not only at the direct effects of climate but also at the mediator and moderator relationships between climate and other organizational variables.

In this regard, Scheneider and Reichers (1983) have laid down the foundations about the causes and origins of the climate construct which remain relevant and which provide the basic

\footnotetext{
2 It is not the intention of this paper to dictate or prescribe what these policies, practices and procedures should be. Each firm will have to navigate their own organizational landscape in order to come up with their own version of policies and practices that reinforce and strengthen its sustainability climate.
} 
underpinnings of most climate research. The notion of a strong organizational climate as a function of employees' social interaction can be traced back to Scheneider and Reichers's (1983) 'interactionist' perspective in which employees become socialized into the prevailing and salient aspects of their work environment. Ashforth (1985) explained that these interactions occur through employees' direct inputs (i.e. their observations, their actions and the reactions they provoke) into the collective sense-making process and through their effects on the work environment itself. Over time, this process helps them to adopt and adhere to the salient organizational aspects, and enables a shared perception of the organizational climate to be formed. Because organizational climate is more 'shallow' than culture in the extent to which it penetrates organizational members' consciousness it operates at the level of their attitudes and visible behaviour. Hence, the specific organizational climate that an organization wishes to promote, say, safety or sustainability, can be enacted and manipulated within a relatively short time frame without undermining the core cultural profile that the organization wants to retain due to the stable and enduring forms of embeddedness of culture. As climate operates at a more accessible level than culture, it can logically be identified within the broader construct of organizational culture. Of course, what this implies is that organizational climate does not exist independently of the organizational culture but it is intrinsically tied to and supported by the organization's deeper cultural characteristics. Rather than conflating the two, which seems to be the case in most CM studies, it is important to differentiate their unique attributes due to the distinct conceptual properties between the two. As discussed earlier, these differences distinguish the ways in which they are formed and hence, ought to be analysed. Among other things, this means that it is easier to change or manipulate organizational climate through short-term management interventions that are aimed at achieving specific organizational goals while organizational culture is often not amenable to such changes due to its entrenched nature (Moran and Volkwein, 1992).

Once formed, a strong organizational climate sends powerful psychological cues to individuals which enable them to construe particular organizational aspects in the same way, hence 
inducing 'uniform expectancies regarding the most appropriate response pattern, provide adequate incentives for the performance of that response pattern, and instil the skills necessary for its satisfactory construction and execution' (Mischel, 1973, p. 276). It is in these terms that climate can be viewed as organizational situations that provide psychological meaning for inducing individual conformity and consistency in behaviour and attitude. This is supported by Blumer's (1986) work on symbolic interactionism, whereby individuals derive meanings of their world through the social interactions that they have with one another and, that these meanings are modified through an interpretative process based on their experiences and encounters. This would imply that in circumstances where a strong organizational climate exists, there is more likelihood for individuals to interact with, and experience and encounter the same strong environmental cues which would then help shape the basis of the meanings that the environment has for them. However, this line of reasoning does not preclude factionalism and divisions from happening in an organization if individuals do not align themselves with the prevailing organizational climate, but instead draw their own interpretations of the situation. Based on these premises, one would argue, therefore, that a weak organizational climate would tend to lead to such non-alignment than when a strong climate exists. A weak climate is where the organizational situation is interpreted as ambiguous by organizational members and does not become a meaningful construct in guiding behaviours and hence, conformity. Climate strength can therefore be usefully conceptualised as the extent of within-group variability in climate perceptions by organizational members; where less within-group variability in perceptions indicates a stronger climate (Schneider et al., 2002).

\section{Organizational climate as behavioural and attitude guidance}

The well-documented effects of organizational climate on various organizational-level and individual-level outcomes suggest that it is important to understand the processes by which organizational climate enables individuals to adopt the desired attitudes and behaviours that, in the collective, are necessary for achieving organizational goals. Here, the focus is not on identifying the 
type or the content of particular organizational practices or procedures but rather on the processes in which the features of the organizational practices facilitate employees to develop the appropriate responses which consequently form a collective sense of what is organizationally valued and expected. While it is not uncommon within the construction industry to encounter distinct perceptions between senior management and site-based operatives about say, sustainability or safety issues, this does not imply that the latter will necessarily contradict or sabotage the implementation of an overarching set of organizational values. This view supported by Bowen and Ostroff's (2004) work in which they have operationalized the climate construct by examining the 'strengths' of different HRM systems and HRM-firm performances and found that there are direct linkages between the two. Hence, the content of a particular organizational practice or procedure normally corresponds strategically with the particular objective that the organization is interested in achieving (e.g. safety, innovation, sustainability, etc.). Process, however, differs from content because it focuses on how the specific organizational practice can be effectively designed and implemented to create a strong shared perception about the content which might ultimately lead to the desired organizational outcomes. Bowen and Ostroff (2004) further pointed out that even in situations where specific content are in place, they may still not elicit the appropriate collective behaviours and attitudes needed for effectiveness if individual organizational members interpret the practices idiosyncratically, thus diminishing the strength of collective, shared perceptions (p. 206). This then leads to the pertinent question of what are the underlying processes that enables a climate strong enough to guide organizational members' attitude and behaviours?

Research suggests that a strong climate that effectively conveys unambiguous messages to employees about what constitutes appropriate behaviour has to have distinctiveness, consistency, and consensus (Mischel, 1973; Delmotte et al., 2012). According to Bowen and Ostroff (2004), the distinctiveness aspect of the climate is characterised by organizational situations that stand out and which capture the attention of employees and arouse their interests. This in turn means features that offer visibility, understandability, legitimacy of authority, and relevance. Indeed, there is 
emerging empirical evidence within the construction industry that firms' sustainability actions are gaining maturity through better integration between firms' sustainability goals and their work practices (Gluch et al. 2014; Reyes-Rodríguez et al., 2016). Based on surveys of Swedish and Danish construction firms, they have respectively found a clear relationship between firms' increased awareness, strategic intent and changing attitude towards sustainability issues (i.e. hence increasing visibility, understandability, legitimacy of authority and relevance) with greater variety and intensity of sustainability activities and actions being undertaken. Reinforced by these features, the organizational situations and their intended messages are more likely to be interpreted uniformly by employees. When this is emphasized and repeated over time it provides consistency in the way employees make appropriate attributions about what behaviours are expected and valued. However, the risks of inconsistency can arise easily enough when a difference between espoused value and inferred values exist (Martin and Siehl, 1983). For instance, senior management may espouse a value of ethical business practice, but employees may infer the contrary if the performance and reward system do not reinforce these practices. Hence, providing consistent messages that convey compatibility and stability will not only reduce the deleterious effects of cognitive dissonance among employees but more crucially, it fosters consensus as to what is expected of them and what they expect of the organization in return. Consensus leads to stronger shared perceptions among employees which are required to enhance the legitimacy and acceptability of the key event-effect relationships that an organization wants to establish because these in turn, serve as a platform from which desired behaviours and attitudes emerge.

\section{Climate analysis as an alternative perspective to achieving organizational sustainability goals}

Numerous researchers have either directly suggested or indirectly alluded to the important role that culture plays in attaining sustainability goals particularly at the organizational level and industry-level (e.g. Boyd and Schweber, 2012; Feige et al., 2011). In many disciplines, and increasingly in $\mathrm{CM}$, the research imperative of situating the complex interplay between human 
behaviours and actions within the context in which they occur necessitates the viewing of culture as a dominant construct whereby its effects and consequences need to be understood, analysed and explained (Phua, 2013). However, this paper argues that focusing solely on the cultural elements, or more precisely advocating changing or altering aspects of culture to achieve strategic organizational goals often neglects the more fundamental consideration of how this is to be practically and realistically achieved? The construction industry is abound with examples of such superficial culturechanging paradigms that supposedly lead to better performance outcomes, i.e. improved trust and cooperation between project participants through partnering arrangements (Barlow et al., 1997; Bennett and Jayes, 1995). The hegemonic approach of prescribing culture change in these instances risks simplifying the intricacies and entrenched nature of culture's assumptions, values and belief systems in influencing behaviours and organizational outcomes. Indeed, many inferences made about the role of culture in the $\mathrm{CM}$ literature are actually studies that highlight the prevalent attitudes and shared perceptions surrounding a particular set of issues (i.e. claims culture - Rooke et al., 2003; TQM culture - Yong and Pheng, 2008; innovation culture - Gray and Davies, 2007; waste culture - Teo and Loosemore, 2001). What is revealed in all these studies is that shared perception of common practices which is typically associated with dimensions of organizational climate is taken to be synonymous with culture. Yet, without going deeper into analysing how the underlying values, beliefs and assumptions affect these issues, it is difficult to determine whether the behaviour of organizational members matches the espoused rhetoric or more importantly, how the desired behaviour can be harnessed. Hence, in conceptual terms, and drawing from Rentsch's (1990) compelling synthesis of the interaction and qualitative differences between climate and culture, this paper argues that the use of culture as an explanatory framework in the majority of studies that are primarily concerned with the extent to which shared perceptions influence behaviours and attitudes is one analytical level removed from the more relevant climate analysis. Because culture is perceived as a complex concept, shared perceptions and meanings of organizational events are just one component of most definitions of culture. In trying to study the development of shared perceptions, 
culture researchers have to assess indirectly the structures of perceptions, beliefs and values, and patterns of symbolic relationships and meanings (Rentsch, 1990). This is often a much bigger challenge than many researchers care to account for. In the CM discipline, it is not uncommon to find that the way in which research questions are framed in research papers indicate that the researchers are in fact interested in studying climate issues rather than culture issues (Phua, 2013). More appropriately, therefore, adopting a climate perspective in this type of analysis makes more sense because it addresses directly how employees' behaviour is shaped by prevailing organizational characteristics through expectations of how certain behaviours will be rewarded and supported in an organization.

One productive area in the $\mathrm{CM}$ discipline that employs climate analysis has been construction safety research. Much work has been done to understand not the safety culture but rather the effectiveness of a strong safety climate in improving construction safety outcomes (Lingard et al., 2010; Melia et al., 2008; Jorgensen et al., 2007; Gillen et al., 2002). Recently, a paper by Shen et al. (2015) focusing on the operationalization of psychological safety climate at the individual level is a welcome departure from the previous emphasis in CM literature on broader structural aspects (i.e. safety standardization, formalization) of organizational climate. The conceptual rationale of focusing on climate analysis for safety research is particularly useful because it enables researchers to understand how shared perceptions amongst employees can be enhanced through certain safety behaviours that are supported and rewarded in the organization (see Bowen, and Ostroff, 2004). Organizational practices, procedure and policies become the most important sources of rewards and support that shape behaviour because they provide employees with a psychologically and socially meaningful basis to interpret and make sense of their environment. In other words, these organizational aspects serve as climate indicators that reinforce the priority areas, which may differ from mere rhetorical pronouncements or formal declarations concerning the same issues. Studies have repeatedly shown that safety climate perception is largely dependent on the priority that is perceived to be placed on safety through relevant, coherent and conspicuous 
practices and policies (see Clarke, 2006 for meta-analytic review). As noted by Zohar and Luria (2004, p.322) these organizational aspects are like 'in vivo tests that reveal "the way things are around here" from a psychological, motive-relevant perspective, informing consensual behaviour-outcome expectancies'.

Adopting the climate perspective, it can be similarly argued that sustainability goals can be effectively achieved through instilling of appropriate behaviours and attitudes among organizational members. Notwithstanding the types of formalised strategic components that we now understand to be crucial to the attainment of such goals, noticeably absent from the $\mathrm{CM}$ literature is the considerations that go beyond focusing on construction firms' unique resource-based profile and dynamic capabilities to advance their sustainability goals. This is a significant omission because in related studies on corporate social responsibilities (CSR), researchers have found that the extent to which employees will act as 'ambassadors' to drive the organization's CSR program is determined by not only on how efficiently organizations deploy and exploit their scarce resources but also how closely the image put forth in the CSR program aligns with the organization's identity (Collier and Esteban, 2007). This means that employees draw on cues about resource commitment, alignment between elements of the organization's CSR program, emotional engagement, justice, and embeddedness to help formulate a set of commonly shared perceptions about the organization (McShane and Cunningham, 2012).

This paper argues that the same logic can be transposed to sustainability research to explore the development of a 'strong' sustainability climate in guiding behaviour. In the preceding sections, the salient organizational features contributing to climate strength were discussed. The characteristics of a strong sustainability climate (i.e. the distinctiveness, consistency, and consensus nature of practices and policies) are more likely to promote shared perceptions and lead to the emergence of a desired set of sustainable behaviour among organizational members. This occurs because a strong climate fosters similar worldview such that organizational situations lead organizational members to 'see' the situation similarly (see Lingard et al., 2010; Melia et al., 2008 for 
construction specific examples). In short, it is this worldview that gives shape and meaning to the environment a person experiences and acts within. It rarely takes the form of highly developed systematic philosophies but rather act as signals that tend to influence language, thoughts, perceptions, and actions (Morgan, 1980; Gladwin et al., 1995). Therefore, it is this notion of a lessphilosophically grounded concept which explains why climate interventions can be effectively enacted and manipulated by management over a relatively short time frame. This implies a more practical approach which construction firms can look to adopt in order to promote strong collective behaviours and attitudes that align with organizational sustainability goals. While the aim here is not to prescriptively suggest what these behaviours and attitudes ought to be, suffice it to say that they do imply elements that are associated with, for instance, sustainable corporate citizenship and ethics. Underpinned by this perspective, construction firms will need to design and implement appropriate policies and practices (e.g. those focused on fairness, ethics, respect for nature) that promote shared perceptions amongst employees that are linked to the firm's sustainable goals and which also facilitate the inclusiveness of stakeholder engagement.

The behavioural consequences of a strong climate within each organization tend to spill-over to affect broader project-level climate where uniform and clear expectations about rewards and incentives for desired attitudes and behaviours become more readily embraced by different stakeholders. The postulation that such socially-induced compliance and conformity can transcend organizational boundaries is consistent with previous research on the spill-over effects of strong organizational identity (see Phua, 2004; Brown and Phua, 2011). Hence, the role of sustainability climate in broader stakeholder engagement - the kind that involves complex decision making phases, multiple tasks and players - would be based on stakeholders' shifting attitudes and behaviours which would in turn lead to the emergence of practical decision support mechanisms that readily incorporate consensual sustainability criteria to evaluate the design and selection of products, processes, and projects. At this project level, high distinctiveness, consistency and consensus of processes and practices, too, become key to a strong project-level climate as it reduces 
the variance across individual stakeholder's perceptions and contributes to a collective sense-making process that are consistent with the overarching industry sustainability agenda. Indeed, evidence of this already happening within the construction industry is in the area of construction safety.

\section{Conceptual framework for organizational climate research in $\mathrm{CM}$}

As discussed earlier, organizational climate has distinct conceptual properties from organizational culture but at the same time it is situated within the broader construct of organizational culture. It exists and is therefore examinable, at the level where behaviour is visible. The 'visible' vs. 'invisible' aspects of culture and hence, the explication of organizational climate as a distinct but related aspect of organizational culture, is succinctly argued by Moran and Volkwein (1992 p.40) who explained that 'organizational climate exists at the level of cultural forms rather than substance...it consists of perceptions, attitudes, behaviours, and to some extent values. By contrast, the essential substance of culture is relatively invisible and preconscious'. They went further to suggest that 'climate exhibits those behavioural and attitudinal characteristics of participants which are more empirically accessible to external observers. Culture, on the other hand, represents a more implicit feature of organizations' (p. 42).

This difference underscores the need for conceptual clarity between climate and culture research. In CM literature, such conceptual clarity is by and large absent. Although the conceptual basis of organizational climate inevitably links it to organizational culture, this does not necessarily imply that the two should be conflated. Attempts to do so not only obscure important insights into the formation and consequence of organizational climate, its mediation and moderation effects on organizational outcomes, but it also mask the influence that an organization climate has upon its culture and vice versa.

Distinguishing between the two constructs has important practical and managerial implications too. Because climate operates at a more accessible level than culture, it tends to be more readily manipulated or altered through short-term interventions or initiatives to achieve the 
intended organisational change than culture (Moran and Volkwein, 1992). This implies that for much of existing studies in $\mathrm{CM}$ where the central message is about culture change when it is actually climate change that should be discussed, the findings could be counter-productive and of limited use because they do not reveal which culture's deeper aspects are affecting the observed climate changes. From a management viewpoint, this might unnecessarily perpetuate the expectation amongst practitioners that culture is something that can be readily altered to yield short-term outcomes. Hence, in reality, attempts at shifting culture are often met with scepticism by construction practitioners because they rarely result in the anticipated outcomes (see Phua, 2006). As the rhetoric for culture change continues to find its way into the literature, the real impetus is for $\mathrm{CM}$ researchers to be critical about the specific relationships that are being considered. Is it really culture that they are interested in or is it the climate construct that should be operationalized instead? In other words, we should seek to answer two questions: Does focusing on the climate construct explain the phenomenon much more adequately than using the culture construct? Can the antecedents and consequences of climate and its impact on outcomes be identified and differentiated from the antecedents and consequences of culture? This paper argues that shifting the focus from culture research to climate research could be a fruitful avenue in generating practical implications for construction firms given that a high proportion of CM studies are essentially climatederived research aimed at examining the relationships between various observable practices or processes, whether at individual-, organizational- or project-level, and outcomes.

For sustainability research, new practical and research insights can be gained from the conceptual clarity of adopting the climate lens. Specifically, understanding how construction firms can achieve their sustainability goals through their employees demands a climate-based framework which explains the mechanisms by which their attitudes and behaviour can be shaped to align with those organizational goals. In contrast to culture, the climate perspective enables researchers to conceptualize the influence of specific context on human behaviour rather than on understanding the process (i.e. assumptions and beliefs) by which such context develops. The context specific 
nature of climate research usefully means that researchers do not assume that findings have the same deep cultural meaning across different organizational or project settings and hence avoiding the tendency to over-generalise or over-simplify the implications of research findings (Lansley, 1994; Cherns and Bryant, 1984). In this regard, CM researchers have often committed the error of focusing on generalizing about the ubiquity of certain cultures and its consequence (e.g. partnering culture and increased trust) and perpetuating the myth that the assumptions and beliefs underlying these cultures are universally shared and understood, and can be easily enacted (Bresnen and Marshall, 2000).

A practical departure and potentially fruitful research avenue for climate research in $\mathrm{CM}$ is to recognise that the organizational context brought about by the management interventions in each firm will be different/unique and the shared perceptions and reactions of the organizational members who work within each of these contexts will be different. As Schneider et al. (2013, p.379) pointed out, by contrast, management interventions which "focused on cultural change often emphasize on closing the gap between existing and desired cultures, and these are typically captured in measures by asking respondents for both kinds of data. The underlying assumption (hope?) is that, with knowledge, culture can be changed through the right action. Executives implicitly understand that they have somewhat limited direct influence on effecting change because so many issues must be addressed simultaneously throughout the firm". They further added that because culture change is elusive to measure, it could mean that it is challenging for management to create unique, internal processes, policies and procedures (e.g. ethics, fairness, respect for nature) to embed the organization's values and to develop the focused strategic outcomes (e.g. safety, sustainability) and climates that serve as guidelines for behaviour (p.380). In terms of climate for sustainability, rather than inferring generalizability of findings across the board the impetus is to explore and understand what each firm does or has the potential of doing through well-thought out management practices and procedures to strengthen employees' shared perceptions and desired behaviours. This paper argues that a more fine-grained analysis of each organizational context and 
its respective consequences will reveal a more complex yet more meaningful set of drivers underlying the issues of interest. Accordingly, from these discussions, three research propositions are advanced as follows:

Proposition 1: Firms attempting to socially embed sustainability goals within their organizations will do so more successfully by focusing on altering and changing dimensions of organizational climate than firms which are focusing on altering and changing dimensions of organizational culture, ceteris paribus.

Proposition 2: Firm-specific management interventions on internal processes (e.g. ethics, fairness, respect for nature) derived from an organizational climate perspective will shape employees' shared perceptions, attitudes and behaviours on sustainability issues within a shorter time span compared to those derived from an organizational culture perspective (e.g. values and beliefs), ceteris paribus.

Proposition 3: Compared with culture-based management interventions (i.e. those focused on the invisible aspects such as values and beliefs), climate-based management interventions (i.e. those focused on the visible aspects such as processes and procedures) are less enduring and are more adaptable to meeting the changing circumstances of the organization and its attendant shifting organizational goals.

\section{Methodological possibilities}

In practical research terms, researchers employing the climate construct to study organizational functions would, as Glick (1985) succinctly argued, need to ensure that the climate data were aggregated to the organizational level of analysis, and also that the climate measurement was focused on important organizational outcomes (e.g. sustainability goals). This would set such 
type of research apart from other similar individual-level attitudinal research, and it also enables researchers to conduct multiple-levels of analysis of organizations and the subunits (groups) nested within the organizations. This could potentially reveal interesting, and hitherto unexamined main and mediating effects, such as for instance, when a particular subgroup sustainability climate mediated the effects of organizational sustainability climate in terms of employees' shared perceptions and behaviours, or vice versa. This will not only improve the empirical validity of research findings but also will yield results with important managerial implications than has been the case.

Therefore, in testing the above three propositions, it is important that some methodological possibilities are considered. Without being prescriptive, but in line with most hypothetic-deductive studies found in in mainstream management, organization and sub-branches of psychology literature, these propositions will benefit from a positivistic approach which involves applying or developing psychometrically robust measures to explore, quantify and determine the relationships between the variables in context-specific situations. In $\mathrm{CM}$, such studies are drawing more scholarly attention in recent years (e.g. Toor and Ofori 2009; Phua, 2017). Similarly, for the purpose of testing the propositions here, such an approach is useful for shedding light on our understanding of how and why different internal procedures/processes of organizational climates (e.g. ethics) influence individual-level outcomes (e.g. behaviour, shared perceptions) and consequently, organizationallevel outcomes (e.g. sustainability goals) differently. When designed and executed properly, this type of studies can be replicated across different times, settings and locations to generate useful empirical comparative data, which will also improve the validity and reliability of measures over time. Data sources and analysis are not necessarily confined to quantitative means alone, as it is sometimes more appropriate, depending on the nature of their inquiry, for researchers to derive data sources through interviews or observations. This could be a more fruitful avenue for researchers exploring the more subtle effects of various culture constructs. Ultimately, the 
rationalization and articulation of the context and the level of analysis to be studied are essential aspects which will determine the type of data to be collected.

\section{Conclusions}

Research in sustainability has come a long way since it first gained traction some 10 or so years ago. Although the interest in sustainability research during this period has focused heavily on the technical, structural, institutional and policy aspects, there is growing interests in the management and social interactions of sustainability in the current $\mathrm{CM}$ discourse. If we accept that firms choose to embark on a sustainability 'path' by choice in order to improve their competitive advantage, then we also accept that they would possess the necessary dynamic capabilities to ensure it works (Teece et al., 1997). To this end, research focusing on the internal capabilities of firms with respect to their technological, organizational and managerial processes has offered greater understanding of what, how, and why firm-specific drivers lead to some firms being more successful than others in achieving their sustainability goals. Amidst this flourishing line of research, there remains a gap in our understanding of the mechanisms by which firms enable their sustainability goals to be socially embedded within their organizations in order to achieve the desired sustainability performance.

This paper argues that focusing on the tangible drivers alone is no longer sufficient in helping us understand the more nuanced issues that must necessarily arise with the formulation and implementation of strategic sustainability goals. The ease and extent to which firms can successfully execute their sustainability goals lie in no small part on how well they can socially shape the behaviour and attitudes of employees to create a strong level of engagement with the firms' sustainable initiatives. This is not a trivial issue because past research has shown that employees can quickly become disengaged, cynical and acquire negative perceptions about such initiatives if they are deemed to be inauthentic or incongruent with their day-to-day work experiences (McShane and Cunningham, 2011; Slack et al., 2015). In gaining employees' full participation at the organizational 
level, sustainability principles have to become visible and form part of individuals' social sensemaking, such that their shared perceptions align closely with that of the firm's. For this to happen, the conventional wisdom is that firms would require to embark on a process of cultural change such that aspects of the old culture could be replaced with the 'new' sustainability culture. However, this paper argues that mobilising the culture framework for such investigations is unproductive because this only taps into a facet of culture research which is visible and accessible while omitting the complex and unconscious abstractions and meanings of culture. Indeed, much of existing CM research which treats culture as comprising just these visible and accessible dimensions is actually climate-based research. If this type of research is to continue, there are conceptual and empirical merits to separate these two constructs and for researchers to understand the distinction between them and consequently, designing their research and formulating testable hypotheses that explicitly capture the relevant aspects of each of these.

In highlighting the need for more conceptual clarity between culture and climate, and in discussing the utility of the organizational climate framework, there is a need to appreciate the mutually reinforcing properties between the two constructs. As Schein (2000) puts it, "Climate and culture, if each is carefully defined, then become two crucial building blocks for organizational description and analysis" (Schein 2000, pp. xxiv-xxv). Employing the climate framework does not exclude the influence of culture but merely draws out the subtle distinctions between the two. This is further reinforced by Schein (2010) who characterized climate not simply as 'cultural artefacts' but that it is a construct which provides the behavioural (measureable) evidence for the culture of the organizational setting, such that those behaviours form the bases for employees' conclusions about the values and beliefs that characterize their organization. It is hoped that the three research propositions included here will go some way in setting the scene for future research in this area, and more broadly, advance the sustainability discourse within CM discipline beyond the current largely technical, policy and institutional foci. 


\section{References}

Ashforth, B.E. (1985), Climate formation, issues and extensions, Academy of Management Review, $10,837-847$.

Barlow, J., Cohen, M., Jashapara, A. and Simpson, Y. (1997), Towards Positive Partnering, The Policy Press, Bristol UK.

Barney, J. (1991) Firm resources and sustained competitive advantage, Journal of Management, 17, $99-120$.

Bennett, J. and Jayes, S. (1995), Trusting the Team: The Best Practice Guide to Partnering in Construction, The Reading Construction Forum, University of Reading.

Berardi, U (2013), Clarifying the new interpretations of the concept of sustainable building, Sustainable Cities and Society, 8, 72-78.

Bergman, N and Eyre, N. (2011) What role for microgeneration in a shift to a low carbon domestic energy sector in the UK?, Energy Efficiency, 4, 335-353.

Bianchini, F. and Hewage, K. (2012), How "green" are the green roofs? Lifecycle analysis of green roof materials, Building and Environment, 48, 57-65.

Blumer, H. (1986), Symbolic Interactionism: Perspective and Method, University of California Press, California.

Bon, R., and Hutchinson, K. (2000), Sustainable construction: some economic challenges, Building Research \& Information, 28, 310-314.

Bowen, D.E. and Ostroff, C. (2004), Understanding HRM-firm performance linkages: the role of the "strength" of the HRM system, Academy of Management Review, 29, 203-221.

Boyd, P., and Schweber, L. (2012) Variations in the mainstreaming of sustainability: a case study approach. In: Proceedings of the 28th ARCOM Conference, 3 - 5 September 2012, Edinburgh, UK, 1343-1354.

Bresnen, M. and Marshall, N. (2000), Partnering in construction: a critical review of issues, problems and dilemmas, Construction Management and Economics, 18, 229-237. 
Brown, A. D. and Phua, F. T.T. (2011) Subjectively construed identities and discourse: towards a research agenda for construction management, Construction Management and Economics, 29, 83-95.

Carr, J., Schmidt, A., Ford, J., and Deshon, R. (2003), Climate perceptions matter: a meta-analytic path analysis relating to molar climate, cognitive and affective states, and individual level work outcomes, Journal of Applied Psychology, 88, 605-619.

Cherns, A.B. and Bryant, D.T. (1984), Studying the client's role in construction management, Construction Management and Economics, 2, 177-184.

Clarke, S. (2006), The relationship between safety climate and safety performance: a meta-analytic review, Journal of Occupational Health Psychology, 11, 315-327.

Collier, J., \& Esteban, R. (2007). Corporate social responsibility and employee commitment, Business Ethics: A European Review, 16, 19-33.

de Jong, A., de Ruyter, K., and Lemmink, J. (2005), Service climate in self-managing teams: mapping the linkage of team member perceptions and service performance outcomes in a businessto-business setting, Journal of Management Studies, 42, 1593-1620.

Delmotte, J., de Winne, S. and Sels, L. (2012), Toward and assessment of perceived HRM system strength: scale development and validation, The International Journal of Human Resource Management, 23, 1481-1506.

Department of Business, Enterprise and Regulatory Reform, Strategy for Sustainable Construction, (2008) http://webarchive.nationalarchives.gov.uk/+/http:/www.bis.gov.uk/files/file46535.pdf, accessed on 10 October 2017.

Department for Business, Energy and Industrial Strategy (2013), Construction 2025, https://www.gov.uk/government/uploads/system/uploads/attachment data/file/210099/bi s-13-955-construction-2025-industrial-strategy.pdf, accessed on 10 October 2017. 
Department for Environment, Food \& Rural Affairs (2010-2017), Greening Government Commitments, https://www.gov.uk/government/collections/greening-governmentcommitments, accessed on 10 October 2017.

Denison, D.R. (1996), What is the difference between organizational culture and organizational climate? A native's point of view on a decade of paradigm wars, Academy of Management Review, 21, 619-654.

du Plessis, C. (2007) A strategic framework for sustainable construction in developing countries, Construction Management and Economics, 25, 67-76.

du Plessis, C., and Cole, R. J. (2011), Motivating change: shifting the paradigm, Building Research \& Information, 39, 436-449.

Feige, A., Wallbaum, H. Krank, S. (2011), Harnessing stakeholder motivation: towards a Swiss sustainable building sector, Building Research \& Information, 39, 504-517.

Fawcett, W., Hughes, M., Krieg, H., Albrecht, S. and Vennström, A. (2012), Flexible strategies for long-term sustainability under uncertainty, Building Research \& Information, 40, 545-557.

Fellows, R. and Liu, A.M.M. (2012), Managing organizational interfaces in engineering construction projects: addressing fragmentation and boundary issues across multiple interfaces, Special Issue on Management Engineering Construction, Construction Management and Economics, $30,653-672$.

Gillen, M., Baltz, D., Gassel, M., Kirsch, L. and Vaccaro, D. (2002), Perceived safety climate, job demands and co-worker support among union and non-union injured construction workers, Journal of Safety Research, 33, 33-51.

Gladwin, T.N., Kennelly, J.J., and Krause, T.S.(1995), Shifting paradigms for sustainable development: implications for management theory and research, Academy of Management Review, 20, 874-907.

Glick, W.H. (1985), Conceptualizing and measuring organizational and psychological climate: pitfalls of multilevel research, Academy of Management Review, 10, 601-610. 
Gluch, P., Gustafsson, M. and Thuvander, L. (2009), An absorptive capacity model for green innovation and performance in the construction industry, Construction Management and Economics, 27, 451-64.

Gluch, P., Gustafsson, M., Thuvander, L. and Baumann, H. (2014), Charting corporate greening: environmental management trends in Sweden, Building Research \& Information, 42, 318329.

Gray, C. and Davies, R.J. (2007), Perspectives on experiences of innovation: the development of an assessment methodology appropriate to construction project organizations, Construction Management and Economics, 25, 1251-1268.

Häkkinena, T., and Bellonia, K., (2011), Barriers and drivers for sustainable building, Building Research \& Information, 39, 239-255.

Hill, R.C. and Bowen, P.A. (1997), Sustainable construction: principles and a framework for attainment, Construction Management and Economics, 15, 223-239.

Hofstede, G., Neuijen, B., Ohayr, D. and Sanders, G. (1990), Measuring organizational cultures: a qualitative and quantitative study across twenty cases, Administrative Science Quarterly, 35, 286-316.

Hofstede, G. (1991), Culture and Organization: Software of the Mind, New York: McGraw-Hill. Huang, R.Y and Hsu. W.T. (2011), Framework development for state-level appraisal indicators of sustainable construction, Civil Engineering and Environmental System, 28, 143-164.

James, L. and Jones, A. (1974), Organizational climate: a review of theory and research, Psychological Bulletin, 18, 1096-1112.

Jorgensen, E., Sokas, R.K. , Nickels, L., Gao, W. and Gittleman, J.L. (2007), An English/Spanish safety climate scale for construction workers, American Journal of Industrial Medicine, 50, 438-444. Joyce, W.F. and Slocum, J.(1984), Collective climate: agreement as a basis for defining aggregate climate in organizations, Academy of Management Journal, 27, 721-742. 
Kuenzi M. and Schminke, M. (2009) Assembling fragments into a lens: A review, critique, and proposed research agenda for the organizational work climate literature, Journal of Management, 35, 634-717.

Lansley, P. (1994), Analysing construction organizations, Construction Management and Economics, $12,337-348$.

Li, B. and Yao, R. (2012), Building energy efficiency for sustainable development in China: challenges and opportunities, Building Research \& Information, 40, 417-431.

Lingard, H.C., Cooke, T. and Blismas, N. (2010), Safety climate in conditions of construction subcontracting: a multi-level analysis, Construction Management and Economics, 28, 813825.

Lomas, K.J. (2009), Decarbonizing national housing stocks: strategies, barriers and measurement, Building Research \& Information, 37, 187-191.

Lowe, R. and Oreszczyn, T . (2008) Regulatory standards and barriers to improved performance for housing, Energy Policy, 36, 4475-4481.

Martin, J. and Siehl, C.J. (1983), Organizational customer and counterculture: an uneasy symbiosis, Organizational Dynamics, 12, 52-64.

Martin, K., and Cullen, J. (2006), Continuities and extensions of ethical climate theory: a metaanalytical review, Journal of Business Ethics, 69, 175-194.

McShane, L. and Cunningham, P. (2012), To thine own self be true? Employees' judgments of the authenticity of their organization's corporate social responsibility program, Journal of Business Ethics, 108, 81-100.

Mårtensson, K. and Westerberg, K. (2016), Corporate environmental strategies towards sustainable development, Business Strategy and the Environment, 25, 1-9.

Melia, J.L., Mearns, K., Silva, S.A. and Lima, M.L. (2008), Safety climate responses and the perceived risk of accidents in the construction industry, Safety Science, 46, 949-958. 
Mischel, W. (1973), Toward a cognitive social learning conceptualization of personality, Psychological Review, 80, 252-283.

Moran, E.T. and Volkwein, J.F. (1992), The cultural approach to the formation organizational climate, Human Relations, 45, 19-47.

Morgan, G. (1980), Paradigms, metaphors, and puzzle solving in organization theory, Administrative Science Quarterly, 25, 605-622.

Neal, A. and Griffin, M.A. (2006), A study of the lagged relationships among safety climate, safety motivation, safety behaviour, and accidents at the individual and group levels, Journal of Applied Psychology, 91, 946-953.

Nicol, L.A. (2011), The role of institutional regimes in motivating change for sustainable housing, Building Research \& Information,39, 459-472.

O'Reilly, C., Chatman, J., and Caldwell, D. (1991), People and organizational culture: a profile comparison approach to assessing person-environment fit, Academy of Management Journal, 34, 487-516.

Oliver, C. (1991), Strategic responses to institutional processes, Academy of Management Review, $18,145-179$.

Oreszczyn, T. and Lowe, R. (2010), Challenges for energy and buildings research: objectives methods and funding mechanisms, Building Research \& Information, 38, 107-22.

Patterson, M., Warr, P., and West, M (2004), Organizational climate and company productivity: the role of employee affect and employee level, Journal of Occupational and Organizational Psychology, 77, 193-216.

Phua, F.T.T. (2004) The antecedents of cooperative behaviour among project team members: an alternative perspective on an old issue. Construction Management and Economics, 22, $1033-$ 1045.

Phua, F.T.T. (2006) When is construction partnering likely to happen? An empirical examination of the role of institutional norms, Construction Management and Economics, 24, 615-624. 
Phua, F.T.T. (2013), Construction management research at the individual level of analysis: current status, gaps and future directions, Construction Management and Economics, 31, 167-179.

Phua, F.T.T. (2017), Does the built-environment industry attract risk-taking individuals? Construction Management and Economics, 35, 207-217

Rentsch, J. R. (1990). Climate and culture: Interaction and qualitative differences in organizational meanings, Journal of Applied Psychology, 75, 668-681.

Reyes-Rodríguez, J.F., Ulhøi, J.P. and Madsen, H. (2016), Corporate environmental sustainability in Danish SMEs: A longitudinal study of motivators, initiatives, and strategic effects, Corporate Social Responsibility and Environmental Management, 23, 193-212.

Rijala, H.B., Humphreys, M.A. and Nicol, J.F. (2009), Understanding occupant behaviour: the use of controls in mixed-mode office buildings, Building Research \& Information, 37, 381-96.

Rooke, J., Seymour, D., Fellows, R. (2003), The claims culture: a taxonomy of attitudes in the industry, Construction Management and Economics, 21, 167-174.

Schein (2000), Sense and nonsense about culture and climate, in Ashkanasy. N.M., Wilderom, C.P.M., and Peterson M.F., (Eds). Handbook of Organizational Culture and Climate, Thousand Oaks, CA: Sage.

Schein, E.H. (2010), Organizational Culture and Leadership, $4^{\text {th }}$ Edition, San Francisco: Josey-Bass. Schneider, B. and Reichers, A. (1983), On the etiology of climates, Personnel Psychology, 36, 19-39. Schneider, B (1990), Organizational Climate and Culture, San Francisco: Josey-Bass.

Schneider, B., Salvaggio, A., and Subirats, E. (2002), Climate strength: a new direction for climate research, Journal of Applied Psychology, 60, 318-328.

Schneider, B., Ehrhart, M.G., and Macey, W.H. (2013), Organizational climate and culture, Annual Review of Psychology, 64, 361-388

Schweber, L. and Harty, C. (2010) Actors and objects: a socio-technical networks approach to technology uptake in the construction sector, Construction Management and Economics, 28, $657-74$. 
Schweber, L. and Leiringer, R. (2012), Beyond the technical: a snapshot of energy and buildings research, Building Research \& Information, 40, 481-492.

Schweber, L., Lees, T. and Torriti, J. (2015) Framing evidence: policy design for the zero carbon home. Building Research and Information, 43, 420-434.

Scott, M., \& Rothman, H. (1994), Companies With a Conscience, New York: Citadel Press.

Shen, L., Wu, Y., and Zhang, X. (2011), Key assessment indicators for the sustainability of infrastructure projects, Journal of Construction Engineering and Management, 137, 441-451

Shen, Y.Z., Tuuli, M.M., Xia, B., Koh, T.Y., and Rowlinson, S. (2015), Toward a model for forming psychological safety climate in construction project management, International Journal of Project Management, Volume 33, 223-235.

Simons, T. and Roberson, Q. (2005), Why managers should care about fairness: the effects of aggregate justice perceptions on organizational outcomes, Journal of Applied Psychology, 88, 432-443.

Slack, R.E., Corlett, S., and Morris, R. (2015), Exploring employee engagement with (corporate) social responsibility: A social exchange perspective on organisational participation, Journal of Business Ethics, 127, 537-548.

Smith-Crowe, K., Burke, M., and Landis, R. (2003), Organizational climate as a moderator of safety knowledge-safety performance relationships, Journal of Organizational Behavior, 24, 861876.

Summerfield, A.J., Pathan, A., R. J. Lowe, R.J., and Oreszczyn, T. (2010) Changes in energy demand from low-energy homes, Building Research \& Information, 38, 42-49.

Teece, D. J., Pisano, G., and Shuen, A. (1997) Dynamic capabilities and strategic management, Strategic Management Journal, 18, 509-517.

Teo, M.M. and Loosemore, M. (2001), A theory of waste behaviour in the construction industry, Construction Management and Economics, 19, 741-751. 
Toor, S. And Ofori, G. (2009) Authenticity and its influence on psychological well-being and contingent self-esteem of leaders in Singapore construction sector, Construction Management and Economics, 27, 299-313

Torriti, J (2012), Multiple-project discount rates for cost-benefit analysis in construction projects: a formal risk model for microgeneration renewable energy technologies, Construction Management and Economics, 30, 739-747.

United Nations (2015), Transforming Our World: The 2030 Agenda for Sustainable Development, https://sustainabledevelopment.un.org/content/documents/21252030\%20Agenda\%20for\% 20Sustainable\%20Development\%20web.pdf, accessed on 10 October 2017.

van Bueren, E. and de Jong, J. (2007), Establishing sustainability: policy successes and failures, Building Research \& Information, 35, 543-556.

Yong, K.T. and Pheng, L.S. (2008), Organizational culture and TQM implementation in construction firms in Singapore, Construction Management and Economics, 26, 237-248.

Zohar, D. and Luria, G. (2004), Climate as a social-cognitive construction of supervisory safety practices: scripts as proxy of behaviour pattern, Journal of Applied Psychology, 89, 322-333. 